\title{
BIOLOGIA E CONTROLE MICROBIANO DE Urbanus acawoios (WILLIAMS, 1926) (LEPIDOPTERA: HESPERIIDAE): II. PATOLOGIA E SUSCEPTIBILIDADE EM LARVAS INFECTADAS POR Bacillus thuringiensis var. kurstaki (H-3a:3b).
}

\author{
Manoel Dias NOGUEIRA ${ }^{1 \dagger}$, Mohamed E. M. HABIB ${ }^{2}$
}

RESUMO - Devido à falta de informaçōes sobre Urbanus acawoios (Williams, 1926) (Lepidoptera: Hesperiidae), e pelos danos severos por ele causados em árvores de Clitoria racemosa, o presente trabalho foi desenvolvido sob condições de laboratório para verificar a possibilidade de utilizar Bacillus thuringiensis var. kurstaki ( $\mathrm{H}-3 \mathrm{a}: 3 \mathrm{~b}$ ) como agente microbiano para o seu controle. $\mathrm{O} \mathrm{pH}$ do intestino médio do hesperídeo mostrou ser bastante alcalino, variando de 8,4 a 9,2 (média de 8,7 ), indicando a possibilidade das larvas serem susceptiveis ao patógeno. Os ensaios confirmaram a alta susceptibilidade a dosagens equivalentes a $110 \mathrm{~g} / \mathrm{ha}$, resultando em tempos letais medianos $\left(\mathrm{TL}_{50}\right)$ de $42,28,37,18,28,00$ e 51,87 horas para larvas de $3^{\circ}, 4^{\circ}$, inicio e final do $5^{\circ}$ instares, respectivamente. Três outras dosagens $(80,150$ e $280 \mathrm{~g} / \mathrm{h})$ foram aplicadas para larvas do $3^{\circ}$ instar, resultando em TLs50 de 42,62 , 30,77 e 30,06 horas, respectivamente. Descrições detalhadas sobre os sintomas externos nas larvas infectadas foram dadas. As alterações histológicas do intestino médio afetado pela d-endotoxina de $B$. thuringiensis foram descritas. Os resultados obtidos no presente trabalho revelam a grande possibilidade de controlar esta praga utilizando-se produtos e formulados à base desta bactéria.

Palavras-chave - Bacillus thuringiensis var. kurstaki (H-3a:3b), patologia, Amazônia brasileira, Clitoria racemosa.

Biology and Microbial Control of Urbanus acawoios (Williams, 1926) (Lepidoptera: Hesperiidae): II. Pathology and Susceptibility Studies in Larvae Infected by Bacillus thuringiensis var. kurstaki (H-3a:3b) .

ABSTRACT - Due to the lack of information concerning Urbanus acawoios (Williams, 1926) (Lepidoptera: Hesperiidae), and the severe damage caused by it in Clitoria racemosa trees in Manaus, $\mathrm{AM}$, the present research was conducted. The study was undertaken under laboratory conditions, in order to investigate the possibility of its microbial control, utilizing a commercial formulation, Dipel, based on Bacillus thuringiensis var. kurstaki ( $\mathrm{H}-3 \mathrm{a}: 3 \mathrm{~b})$. The larval mid-gut contents of this insect species showed to be highly alkaline, with a pH varying between 8.4 and 9.2 , with an average of 8.7 , indicating initially, a possible susceptibility of the larval stage to such a pathogen. Posteriorly, Such an indication, was confirmed by bioassays. During the preliminary tests, a dosage, equivalent to $110 \mathrm{~g} / \mathrm{ha}\left(17.40 \mathrm{IU} / \mathrm{cm}^{2}\right.$ of leaf-covered area) was utilized and resulted in median lethal times $\left(\mathrm{LTs}_{50}\right)$ of $42.28,37.18,28.00$ and 51.87 hours for the $3^{\text {rd }}, 4^{\text {th }}$, beginning of the $5^{\text {th }}$ and end of the $5^{\text {th }}$ instar, respectively. Giving more attention for the $3^{\text {th }}$ instar larvae, three dosages were applied: $80 \mathrm{~g} / \mathrm{ha}\left(13 \mathrm{IU} / \mathrm{cm}^{2}\right), 150\left(25 \mathrm{IU} / \mathrm{cm}^{2}\right)$ and $280 \mathrm{~g} / \mathrm{ha}\left(45 \mathrm{IU} / \mathrm{cm}^{2}\right)$. In this case, the $\mathrm{LTs}_{50}$ were calculated as $42.62,30.77$ and 30.06 hours, for each dose, respectively. External symptoms of the bacterial disease were studied among $5^{\text {th }}$ instar infected larvae. Detailed description of these symptoms is given. The mid-gut histopathological changes caused by the d-endotoxin of $B$. thuringiensis are also described. The results obtained during the present work could indicate applications of $B$. thuringiensis, as a promising method for the microbial control of this urban pest.

Key-words - Brazilian Amazon, Bacillus thuringiensis var. kurstaki (H-3a:3b), pathology, Clitoria racemosa.

It‘"In memoriam" - Instituto Nacional de Pesquisas da Amazônia - INPA, Manaus - AM.

${ }^{2}$ Universidade Estadual de Campinas - UNICAMP, Campinas, SP. E-mail: mohamed@reitoria.unicamp.br. O segundo autor deste trabalho deixa registrado aqui a saudade que os entomólogos e demais pesquisadores do INPA sentem pelo falecimento precoce do primeiro autor, o jovem Manoel Dias Nogueira. 


\section{INTRODUÇÃO}

A importância econômica, juntamente com dados bio-ecológicos e descrições morfológicas de Urbanus acawoios (Williams, 1926) (Lepidoptera: Hesperiidae) e a sua interação com a palheteira, Clitoria racemosa (Leguminosae), foram detalhados por Nogueira \& Habib (Artigo submetido à publicação). Registros anteriores sobre o comportamento e a bionomia desta espécie são desconhecidos.

Uma revisão sobre as interações entre bactérias cristalíferas e insetos pode ser encontrada em Habib (1982) e Habib \& Andrade (1998).

O presente trabalho tem como objetivo estudar a patologia e susceptibilidade de larvas de Urbanus acawoios (Williams, 1926) (Lepidoptera: Hesperiidae) infectadas por Bacillus thuringiensis var. kurstaki (H-3a:3b). Tal estudo levará a estabelecer uma alternativa sólida e segura para combater esta praga num ambiente que necessita sempre estar protegido.

\section{MATERIAL E MÉTODOS}

A susceptibilidade de larvas de $U$. acawoios à bactérias cristaliferas utilizando-se o produto comercial Dipel (pó-molhável) à base de Bacillus thuringiensis var. kurstaki $(\mathrm{H}-$ $3 \mathrm{a}: 3 \mathrm{~b})$, tendo como virulência 16.000 Unidades Internacionais (UI) $/ \mathrm{mg}$. O $\mathrm{pH}$ intestinal das lagartas foi determinado com o uso de papel indicador Merck com precisão de 0,2. Os bioensaios foram efetuados, utilizando-se um total de 818 lagartas e 4 diferentes dosagens variando entre 12,79 e $44,51 \mathrm{UI} / \mathrm{m} 2$. As larvas eram mantidas em placas de Petri (10 $\mathrm{cm}$ de diâmetro) (10 em cada). Para as testemunhas, utilizou-se um total de 170 larvas. A aplicação do produto foi feita sob a forma de suspensão em água, na qual as folhas eram mergulhadas para obter-se uma distribuição total e uniforme em toda a área foliar e, após serem postas a secar naturalmente, foram oferecidas às lagartas. As avaliações de TL50 foram realizadas com intervalos de tempo em progressão geométrica; os cálculos foram efetuados de acordo com o modelo proposto por Thompson (1947) e adaptado por Habib (1982). Para os estudos de sintomatologia e histopatologia adotou-se critérios estabelecidos por Habib (1982).

\section{RESULTADOS E DISCUSSÃO}

As larvas de $U$. acawoios revelaram perda de apetite e parada de alimentação como primeiros sintomas da bacteriose, a partir de 60 minutos após a ingestão de folhas de Clitoria racemosa contaminadas por $B$. thuringiensis. $\mathrm{O}$ quadro sintomatológico revelou, em seguida, e após poucas horas da infecção, intensa regurgitação e diarréia. A coloração do tegumento das larvas doentes começou a perder o seu brilho, 10 a 12 horas após a infecção, adquirindo uma coloração fosca que começou a ser substituida por manchas pretas que se espalham gradualmente até atingir o total do corpo da lagarta com o decorrer 
da infecção. Esses sintomas revelam claramente a ocorrência de alterações em nível de tecidos e órgãos internos.

A fase seguinte no quadro sintomatológico foi caracterizada pela perda de agilidade. As larvas tornaram-se progressivamente mais lentas em seus movimentos, até total imobilidade. Através da dissecação das larvas infectadas, verificou-se que o intestino permaneceu cheio de alimentos, entre intactos e mal digeridos, indicando a ocorrência de paralisia intestinal. Não se verificou, entretanto, a ocorrência de paralisia geral, fazendo com que esta espécie fosse colocada na categoria II, segundo a classificação de Heimpel \& Angus (1959) que inclui, entre outras, Brassolis sophorae e Alabama argillacea (Habib, 1982) e Ascia monuste (Ronchi-Teles \& Habib, 1989b).

Na morte, verificada a partir de 18 horas após a infecção, as lagartas adquiriam o aspecto preto carbonizado. Os sintomas pósmortais desencadearam-se rapidamente. Os cadáveres secavam e permaneciam com o aspecto externo preto carbonizado.

De acordo com os dados constantes na Tabela 1, verifica-se que o conjunto dos bioensaios realizados revela a alta susceptibilidade de lagartas de $U$. acawoios a $B$. thuringiensis var. kurstaki.

Para as larvas do $3^{\circ}$ estádio, verificou-se que a ação de 25,16 UI/ $\mathrm{cm}^{2}$ foi o que resultou em menor valor de TL50 (30,77 horas); ou seja, maior eficiência. A dosagem de 44,51 UI/ $\mathrm{cm}^{2}$, embora superior, seria desnecessária, pois não resultou em TL50 menor. As duas doses inferiores apresentaram valores de TL50 similares para o mesmo $3^{\circ}$ estádio.

As larvas no início do $5^{\circ}$ estádio mostraram-se mais susceptiveis que as do $4^{\circ}$ estádio. Para a mesma dose $\left(17,40 \mathrm{UI} / \mathrm{cm}^{2}\right)$, o TL50 foi de 28,00

Tabela 1. TL50, em horas, e intervalo de confiança, para lagartas de $U$. acawoios infectadas por Bacillus thuringiensis var, kurstaki, em laboratório.

\begin{tabular}{lrlllll}
\hline Fase & $\mathrm{n}$ & \multicolumn{2}{l}{ Dosagem } & TL50 & \multicolumn{2}{c}{ Intervalo } \\
\hline 3 instar & 25 & $17,40 \quad$ Ul/cm2 & 42,28 & $38,56-46,37$ & a \\
3 instar & 100 & 12,79 & 42,62 & $37,83-47,53$ & a \\
3 instar & 100 & 25,16 & 30,77 & $27,78-34,92$ & b \\
3 instar & 100 & 44,51 & 30,06 & $27,79-32,51$ & b \\
4 instar & 90 & 17,40 & 37,18 & $34,48-40,10$ & a \\
Início 5 & 33 & 17,40 & 28,00 & $23,11-33,92$ & b \\
Fim 50 & 200 & 17,40 & 51,87 & $47,92-55,14$ & c \\
\hline
\end{tabular}


e 37,18 horas, respectivamente. Comparadas com as larvas do $3^{\circ}$ instar, as do $5^{\circ}$ mostraram-se mais susceptíveis. No final do $5^{\circ}$ ínstar (o último), as larvas revelaram menor susceptibilidade. Nesta fase o inseto pára de se alimentar e começa a entrar nas atividades metabólicas de metamorfose para transformar-se em pupa.

As alterações histológicas detectadas no intestino médio de larvas do $5^{\circ}$ instar de $U$. acawoios, infectadas por $B$. thuringiensis (Fig. 1) revelaram uma dissociação bastante acentuada das células epiteliais, da membrana basal, da musculatura intestinal circular e longitudinal, além da degeneração da membrana peritrófica. Em fases mais adiantadas da infecção, verificou-se a destruição da microvilosidade, uma intensa vacuolização citoplasmática, condensação da cromatina nuclear e início da degeneração das membranas celulares. $\mathrm{Na}$ fase pré-mortal, o epitélio encontrou-se totalmente em estado de degeneração da microvilosidade, do citoplasma, e intensa dissociação e relaxamento das fibras musculares. Com essas alterações histológicas na parede intestinal, o caminho já está aberto para que o patógeno comece a sua invasão na hemolinfa, onde se multiplica causando septicemia e a morte do inseto.

Vários autores fizeram observações semelhantes em outros lepidópteros desde Heimpel \& Angus (1959) em B. mori, Hoopingarner \& Materu (1964) em Galleria mellonella, Sutter \& Raun (1967) em Ostrinia nubilalis, Habib (1968 e 1982) em Anagasta kuhniella e Alabama argillacea, Ebersold et al. (1977) em Pieris brassicae e Ronchi-Teles (1985) em Ascia monuste monuste.

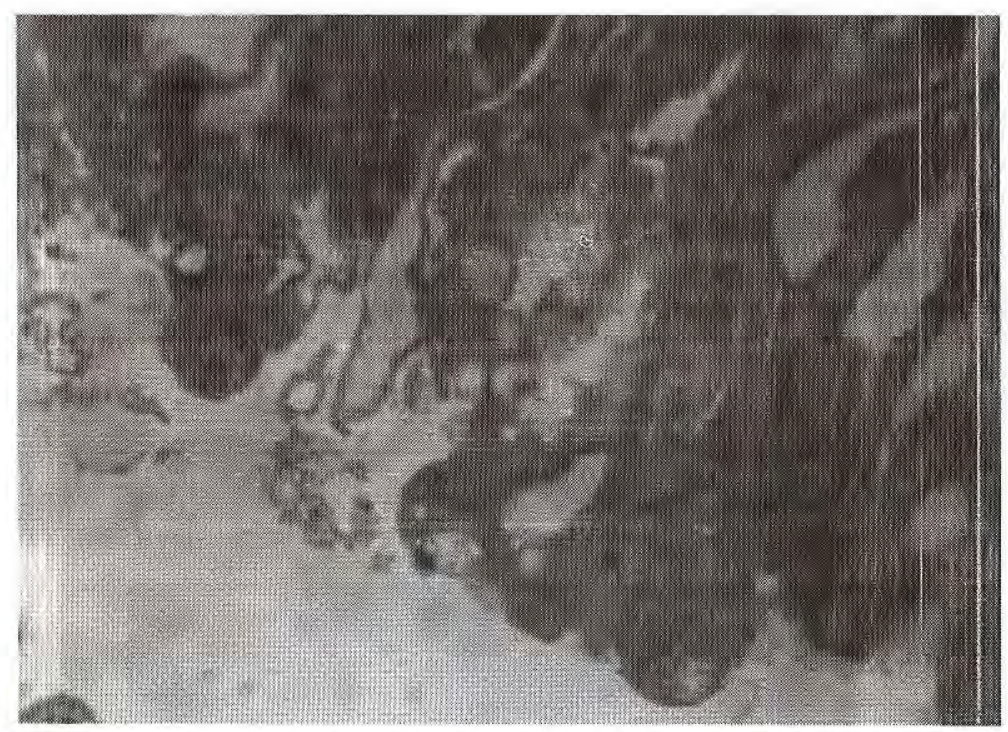

Figura 1. Degeneração e vacuolização citoplasmática do intestino médio de $U$. acawoios. 


\section{Bibliografia citada}

Ebersold, H. R.; Luethy, P.; Muller, M. 1977. Changes in the fine structure of the gut epithelium of Pieris brassicae. Bull. Soc. Entomol. Suis., 50: 269-276.

Habib, M.E.M. 1968. Histopathological studies on the effect of Bacillus thuringiensis Berliner, on the Mediterranean flour moth, Anagasta kuhniella Zeller. Tese de Mestrado. Fac. Eng. Agric. Univ. Alexandria, Egito. 196 pp.

Habib, M.E.M. 1982. Patogenicidade de duas variedades de Bacillus thuringiensis Berliner para larvas de Lepidoptera $e$ Diptera. Tese de Livre Docência. Unicamp. 163 pp.

Habib, M.E.M.; Andrade, C.F.S. 1998. Bactérias Entomopatogênicas. In: Alves, S.B. (ed.). Controle Microbiano de Insetos. FEALQ, Piracicaba, SP. pp 383446.

Heimpel, A.M.; Angus, T.A. 1959. A site of action of cystalliferous bacteria in lepidopterous larvae. J. Insect Pathol., 1: 152 170.

Hoopingarner, R.; Materu, M.E.M, 1964. The toxicity and histopathology of Bacillus thuringiensis Berliner in Galleria mellonella (Linnaeus). J. Insect Pathol., 6: 26-30.

Nogueira, M.D.; Habib, M.E.M. Biologia e controle microbiano de Urbanus acawoios (Williams, 1926) (Lepidoptera: Hesperiidae): I. Descrição morfológica e aspectos bio-ecológicos. (Artigo submetido à publicação)

Ronchi-Tels, B. 1985. Estudos patológicos em lagartas de Ascia monuste monuste (L., 1764) (Lepidoptera: Pieridae) infectadas por Bacillus thuringiensis var. kurstaki $(H-3 a: 3 b)$. Tese de Mestrado. INPA/UA. Manaus, Am.
Ronchi-Teles, B.; Habib, M.E.M. 1989. Patologia em larvas de Ascia monuste infectadas por Bacillus thuringiensis var. kurstaki.II: Susceptibilidade e Virulência. Acta Amazonica, 19: 279-284.

Thompson, W.R. 1947. Use of moving averages and interpolation to estimate median effective dose. Bacter: Ver., 11: 115-145. 